\title{
A Study on Engineering Properties of Reinforced and Unreinforced Soils
}

\author{
Nadakuditi Naga Praveen, Nanduri Kanipaka Ganapathi Rao, \\ Munnangi Bapi Reddy and Namburu Sandeep Kumar \\ ${ }^{1}$ UG Student, Department of Civil Engineering, Koneru Lakshmaiah Education Foundation, \\ Vaddeswaram, AP, India-522502 \\ ${ }^{2}$ Assistant Professor, Department of Civil Engineering, Koneru Lakshmaiah Education Foundation, Vaddeswaram, \\ AP, India -522502,
}

\section{ABSTRACT}

Every year, there were many accidents occurring due to the geotechnical engineering failures such as embankment failures, foundation failures etc. And this count is increasing day by day. There will be many reasons causing these failures and at a time maximum of these were happened because of improper soil investigation. But in many cases even though soil investigation was done perfectly before the construction started, the failures happened. So, in cases like these, after pure investigation was done, we can use reinforcement and sort out those issues. Many people while constructing residential houses never opt these geosynthetic reinforcements due to their false beliefs. Geosynthetic reinforcements help us in making the soil suitable for our constructions. But the difficulty lies in selecting the apt reinforcement respective to that situation. So, when that time comes, one should be aware of all the types available and their properties. So, soil was tested when reinforced with Geotextile and their properties were keenly observed and noted. Results were compared with the normal soil and the difference was also noted. Although Geotextile reinforcement is the largest subcategory of the Geosynthetics, it was still under the research stage in India when compared to the developed countries. In this study, we introduced about Geotextiles, their types, functions, and properties, how they can be useful for Geotechnical constructions and laboratory test results were included which were conducted on Geotextile Reinforced Soil.

KEY WORDS: ENGINEERING PROPERTIES, GEOSYNTHETICS, GEOTEXTILES, REINFORCEMENT, SOIL INVESTIGATION.

\section{INTRODUCTION}

Geosynthetic reinforced soil became so popular for its wide range of application in the construction field such as pavement construction, embankments etc. Use of these geosynthetics helps in the enhancement of the Engineering properties and the bond strength due to the interlocking

\section{ARTICLE INFORMATION}

Received 28th Oct 2020 Accepted after revision 14th Dec 2020 Print ISSN: 0974-6455 Online ISSN: 2321-4007 CODEN: BBRCBA

Thomson Reuters ISI Web of Science Clarivate Analytics USA and Crossref Indexed Journal

\section{Clarivate
Analytics}

NAAS Journal Score 2020 (4.31)

A Society of Science and Nature Publication,

Bhopal India 2020. All rights reserved.

Online Contents Available at: http//www.bbrc.in/

Doi: http://dx.doi.org/10.21786/bbrc/13.15/13 nature of the soil particles. In tropical countries like India, locally available soil is being not used as it is does not meet the requirement of the construction. But if the reinforcement is provided, this soil itself is good enough for the construction of any structure required. Here we have used Cohesionless Soils i.e. Sandy Soils. A thorough study on the Engineering Properties of the Reinforced and Unreinforced soils is conducted. This study presents the difference on usage of Geosynthetics.

Geo Textiles: Geotextiles are permeable fabrics which are a type of reinforcement used in the soil. These are a subcategory of GEOSYNTHETICS. In fact, these are the largest group of the geosynthetics in terms of volume and usage in Geotechnical Engineering. These geotextiles are also textile materials but the thing that separates these 
from the other textile materials like cotton is that these are not natural kind of textiles. These are artificially made from the materials like polypropylene or polyester. These are made from natural or man-made fibres. One more main advantage of the Geo textiles is that these are environment friendly and will have not any kind of adverse effect on mankind. In simple words, these are the permeable textile materials which can be used as reinforcement in soil, rock etc. These Geotextiles are more affective in soil erosion control. Geotextiles will have an ability to complete the functions like separation, filtration, reinforcement, sealing and drainage.

\section{Functions of Geotextiles:}

1.1 Separation: Geotextiles separate different kind of soil particles from combining.

1.2 Filtration: It is the function of Geotextile which allows the water to flow freely and minimize the soil loss.

1.3Reinforcement: Inserting Geosynthetics into the soil mass to increase its strength and resist tensile forces is called as reinforcement.

1.4 Sealing: Geosynthetics minimizes the vertical flow of water into the structure there by protecting the structure.

1.5 Drainage: It is nothing but the ability of the nonwoven geotextile whose structure allows the water to flow through its plane.

\section{Types of Geotextiles:}

Geotextiles are classified into three types. They are:

- Woven Geotextile: A fabric or synthetic material, which helps for the water movement along with the control of soil movement are called as Woven Geotextiles. These types of geotextiles generally help for the separation and filtration functions of the Geotextiles.

- Non-Woven Geotextiles: These types of geotextiles are helpful for filtration, drainage, and reinforcement Functions of geotextiles.

- Knitted Geotextiles: These are mainly and mostly used at the dams. When compared to the other two types of geotextiles, these are not that much developed and researches are still being conducted in this area.

III. Engineering Properties of Soil: There will be a large no of Engineering Properties for a soil. But here we have considered the Engineering parameters such as Permeability, Cohesion and Angle of Internal Friction.

Permeability: Permeability is the rate at which water pass through the soil under the action of hydraulic gradient.

Cohesion: The force which holds the molecules and the particles of soil together is called as the Cohesion.
Angle of Internal Friction: The angle between the normal and resultant forces just when the failure occurs is called as the Angle of Internal Friction. There are certain parameters that are required to get the mentioned Engineering Properties. They are

Relative Density: It is the ratio of a material to the reference material.

Particle Size Distribution: It's an index that indicates what size of particles are present in what proportions in the sample particle group to be measured.

IV. Laboratory Tests: Different Laboratory tests are carried out to find out the solution. Here is the list of Laboratory tests that are carried out:

1. Particle Size Distribution Analysis.

2. Relative Density of the Soil.

3. Constant Head Permeameter Test.

4. Direct Shear Test.

Note: All the mentioned tests are carried out both with and without introducing the Geotextiles as the reinforcement material.

\section{RESULTS AND CALCULATIONS}

\section{Particle Size Distribution:}

Table 1. Particle Size Distribution

\begin{tabular}{|c|c|c|c|c|}
\hline $\begin{array}{c}\text { Sieve } \\
\text { Size }\end{array}$ & $\begin{array}{c}\text { Mass of } \\
\text { Soil } \\
\text { Retained }\end{array}$ & $\begin{array}{c}\text { \% } \\
\text { retained }\end{array}$ & $\begin{array}{c}\text { \%Cumulative } \\
\text { retained }\end{array}$ & $\begin{array}{c}\text { \% } \\
\text { finer }\end{array}$ \\
\hline 4.75 & 5 & 0.5 & 0.5 & 99.5 \\
\hline 2.36 & 13 & 1.3 & 1.8 & 98.2 \\
\hline 1.18 & 75 & 7.5 & 9.3 & 90.7 \\
\hline 0.6 & 260 & 26 & 35.3 & 64.7 \\
\hline 0.3 & 492 & 49.2 & 84.5 & 15.5 \\
\hline 0.15 & 124 & 12.4 & 96.9 & 3.1 \\
\hline 0.075 & 12 & 1.2 & 98.1 & 1.9 \\
\hline Pan & 12 & 1.2 & 99.3 & 0.7 \\
\hline
\end{tabular}

$\mathrm{D} 60=0.495$

$\mathrm{D} 30=0.388$

$\mathrm{D} 10=0.233$

$\mathrm{Cu}$ and $\mathrm{Cc}$ are 2.12 and 1.30, respectively.

Hence the Sand is Poorly Graded Sand (SP).

2. Relative Density:

2.1 Without Reinforcement:

$\mathrm{emax}=0.707127$ 
emin $=0.285102$

enat $=0.545693$

Therefore, Relative Density is 38.25\%.

Hence the Sand is Medium Dense Sand.

\subsection{With Reinforcement:}

$\operatorname{emax}=0.691428$

emin $=0.475315$

enat $=0.545693$

Therefore, Relative Density is 67.43\%.

Hence the Sand is Dense Sand.

3. Permeability:

3.1 With Reinforcement:

Table 2. Permeability with reinforcement

\begin{tabular}{|c|c|c|c|c|}
\hline \multicolumn{5}{|c|}{$\begin{array}{l}\text { CONSTANT HEAD PERMEAMETER TEST } \\
\text { WITH REINFORCEMENT }\end{array}$} \\
\hline S.NO & $\begin{array}{l}\text { Hydraulic } \\
\text { Head (h) }\end{array}$ & $\begin{array}{c}\text { Time } \\
\text { Interval } \\
\text { sec }\end{array}$ & $\begin{array}{l}\text { Quantity } \\
\text { of water } \\
\text { collected } \\
\text { (Q) }\end{array}$ & $\begin{array}{c}\text { Coefficient } \\
\text { of } \\
\text { Permeability } \\
\mathrm{cm} / \mathrm{sec}\end{array}$ \\
\hline 1 & 151.5 & 60 & 250 & 0.00444949 \\
\hline 2 & 151.5 & 60 & 260 & 0.004627469 \\
\hline 3 & 151.5 & 60 & 210 & 0.003737571 \\
\hline 4 & 151.5 & 60 & 230 & 0.00409353 \\
\hline \multicolumn{3}{|c|}{$\mathrm{K}=\mathrm{QL} / \mathrm{Aht}$} & \multirow{4}{*}{\multicolumn{2}{|c|}{0.004227015}} \\
\hline \multicolumn{2}{|c|}{$\begin{array}{l}\text { Length of the } \\
\text { Specimen }(L)\end{array}$} & 12.7 & & \\
\hline \multicolumn{2}{|c|}{ Diameter of the } & 10 & & \\
\hline \multicolumn{2}{|c|}{$\begin{array}{l}\text { Area of the } \\
\text { Specimen(A) }\end{array}$} & 78.5 & & \\
\hline
\end{tabular}

3.2 Without Reinforcement:

Table 3. Permeability without Reinforcement

\begin{tabular}{|c|c|c|c|c|}
\hline \multicolumn{5}{|c|}{$\begin{array}{l}\text { CONSTANT HEAD PERMEAMETER TEST } \\
\text { WITHOUT REINFORCEMENT }\end{array}$} \\
\hline S.NO & $\begin{array}{l}\text { Hydraulic } \\
\text { Head (h) }\end{array}$ & $\begin{array}{c}\text { Time } \\
\text { Interval } \\
\text { sec }\end{array}$ & $\begin{array}{c}\text { Quantity } \\
\text { of water } \\
\text { collected } \\
\text { (Q) }\end{array}$ & $\begin{array}{c}\text { Coefficient } \\
\text { of } \\
\text { Permeability } \\
\mathrm{cm} / \mathrm{sec}\end{array}$ \\
\hline 1 & 151.5 & 60 & 630 & 0.011212714 \\
\hline 2 & 151.5 & 60 & 490 & 0.008720999 \\
\hline 3 & 151.5 & 60 & 560 & 0.009966857 \\
\hline 4 & 151.5 & 60 & 530 & 0.009432918 \\
\hline \multicolumn{3}{|c|}{$\mathrm{K}=\mathrm{QL} / \mathrm{Ah} \mathrm{t}$} & \multirow{4}{*}{\multicolumn{2}{|c|}{$\mathbf{0 . 0 0 9 8 3 3 3 7 2}$}} \\
\hline \multicolumn{2}{|c|}{$\begin{array}{l}\text { Length of the } \\
\text { Specimen }(L)\end{array}$} & 12.7 & & \\
\hline \multicolumn{2}{|c|}{$\begin{array}{l}\text { Diameter of the } \\
\text { Specimen }\end{array}$} & 10 & & \\
\hline \multicolumn{2}{|c|}{$\begin{array}{l}\text { Area of the } \\
\text { Specimen(A) }\end{array}$} & 78.5 & & \\
\hline
\end{tabular}

Note: The Units of the length are $\mathrm{cm}$ and for Area cm2.

\section{Direct Shear Test \\ 4.1 Without Reinforcement}

Table 4. DS Without Reinforcement

\begin{tabular}{|c|c|}
\hline $\begin{array}{c}\text { Normal Stress } \\
\mathbf{~ k g} / \mathbf{c m}^{2}\end{array}$ & $\begin{array}{c}\text { Max Shear Stress } \\
\mathbf{K g} / \mathbf{c m}^{2}\end{array}$ \\
\hline 0.5 & 0.090558 \\
\hline 1 & 0.139321 \\
\hline 1.5 & 0.388087 \\
\hline
\end{tabular}
$\Phi=29.24$
$\mathrm{C}=0.69 \mathrm{kN} / \mathrm{m} 2$
4.2 With Reinforcement

Table 5. DS with Reinforcement

\begin{tabular}{|c|c|}
\hline $\begin{array}{c}\text { Normal Stress } \\
\mathbf{k g} / \mathbf{c m}^{2}\end{array}$ & $\begin{array}{c}\text { Max Shear Stress } \\
\mathbf{K g} / \mathbf{c m}^{2}\end{array}$ \\
\hline 0.5 & 0.2020 \\
\hline 1 & 0.2508 \\
\hline 1.5 & 0.6200 \\
\hline
\end{tabular}

$\Phi=32.23$

$\mathrm{C}=0.80 \mathrm{kN} / \mathrm{m}$

\section{Graphs And Figures \\ 1. Particle Size Distribution Curve}

Figure 1: Particle Size Distribution Curve

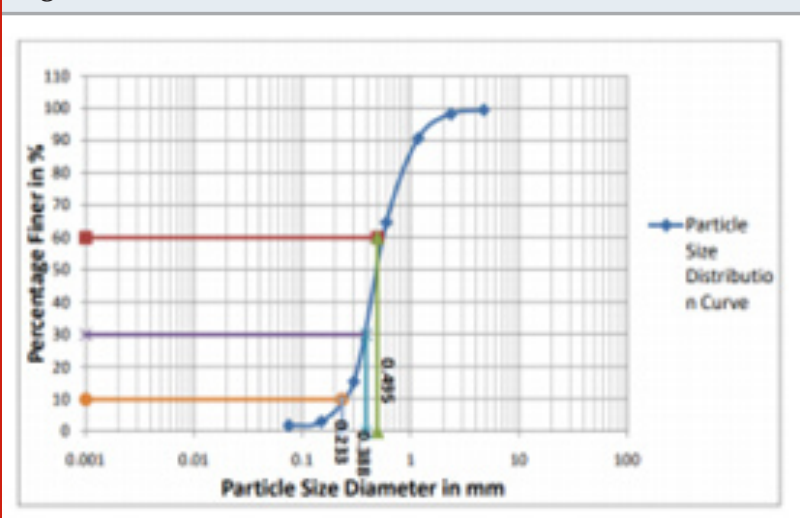

Figure 2: IS Sieves

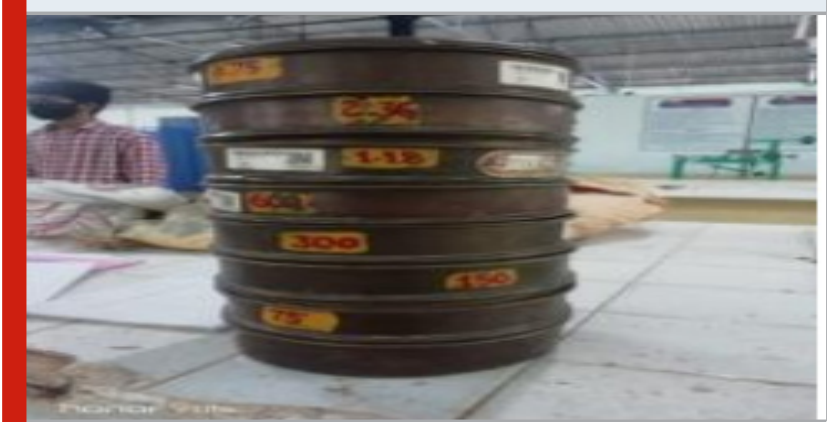




\section{Relative Density}

Figure 3: Relative Density Equipment on Vibrating Table

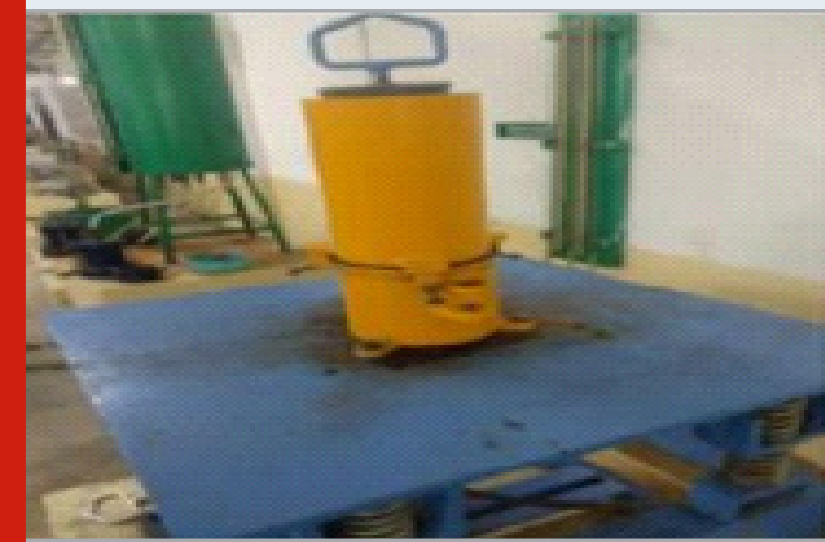

Figure 4: Geotextile in the Relative Density Mould

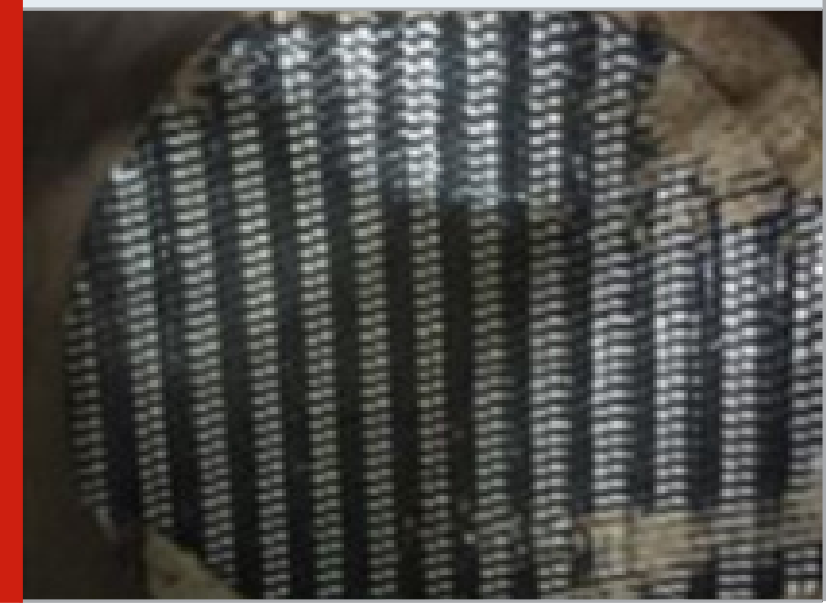

\section{Permeability:}

\section{Figure 5: Constant Head Permeameter}

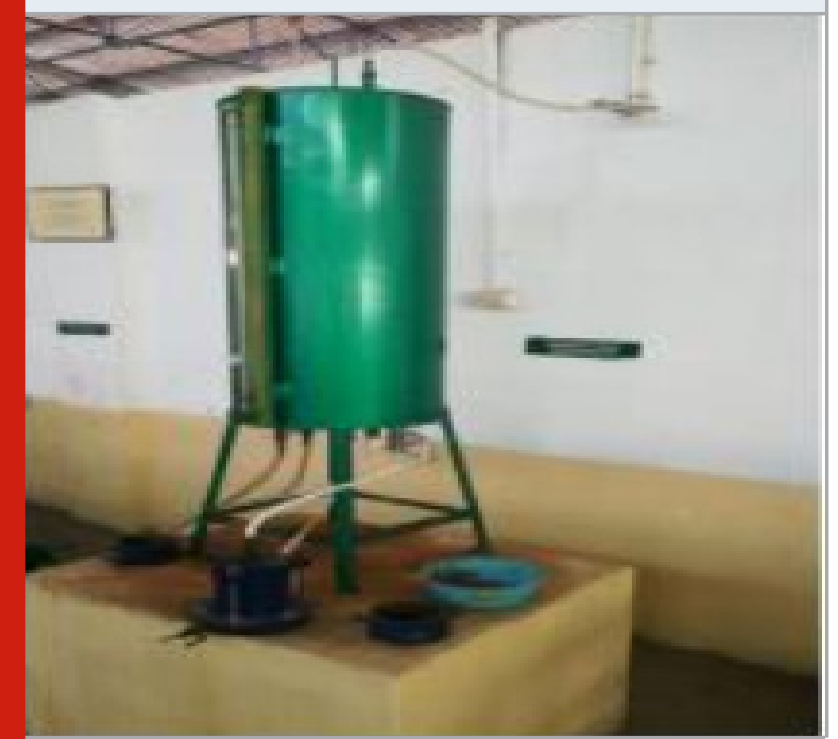

\section{Direct Shear Test}

Figure 6: Direct Shear Graph without Reinforcement

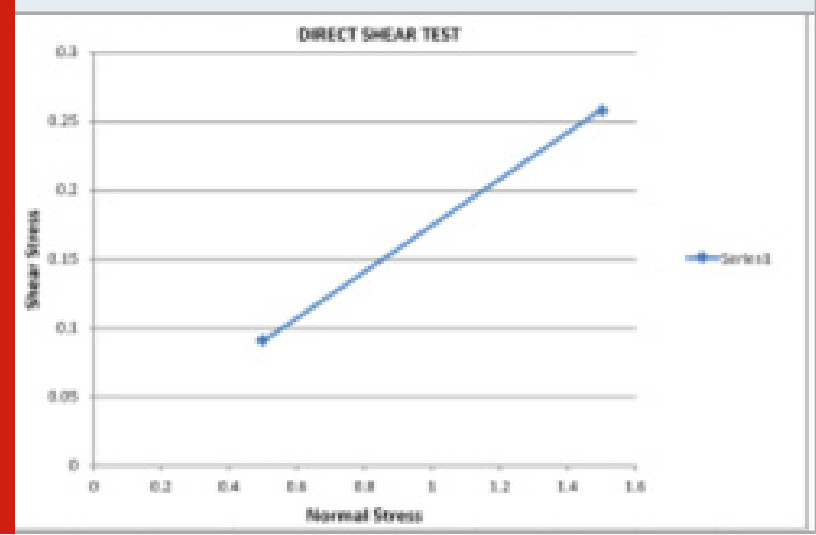

Figure 7: Direct Shear Graph with Reinforcement

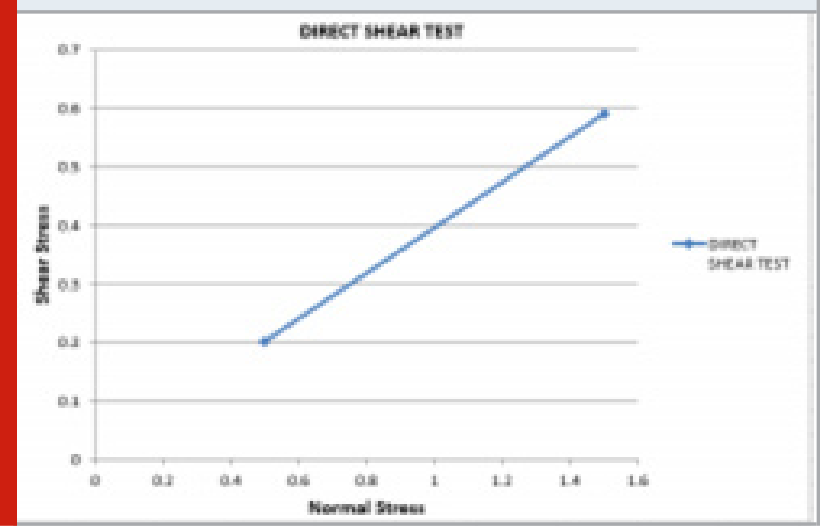

Figure 7a: Direct Shear Test Equipment

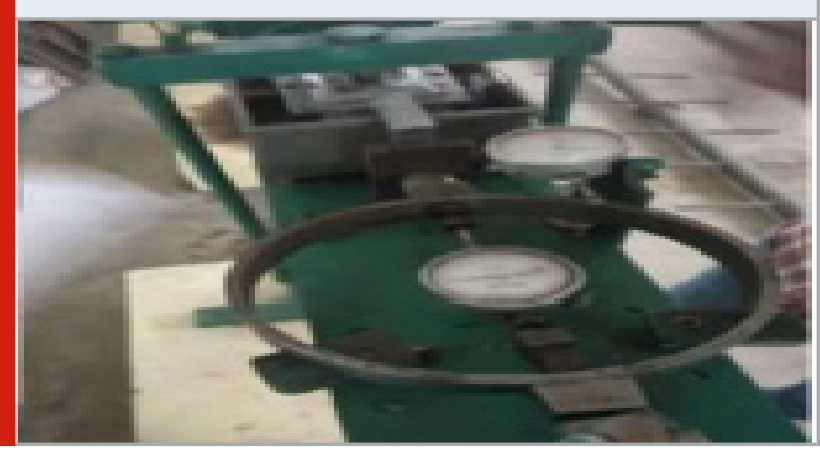

Figure 8: Shear box with Geotextile

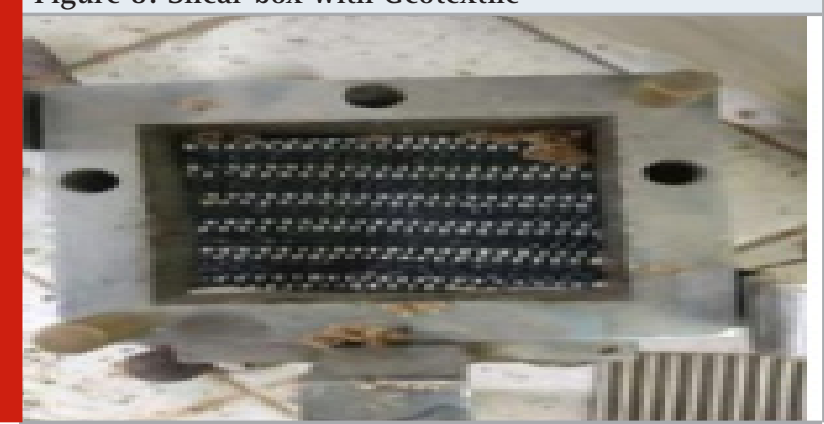




\section{CONCLUSION}

1. In the Particle size distribution, we clearly got the type of soil as the Poorly Graded soil with the Cc value as 1.131 and $\mathrm{Cu}$ value as 2.447.

2. In Relative Density, When the reinforcement is not provided the soil is purely having Medium density i.e. Medium Dense Sand. But when the reinforcement is provided it shows a greater variation making the soil Dense Sand.

3. Constant Head Permeameter Test, the expected result came out i.e. the decrease in the Permeability. The induced geo textile membrane does not allow the water to pass through it, which will be very much useful.

4. In Direct Shear Test, when there is no reinforcement the value of $\Phi$ is comparatively less. But whereas when the reinforcement is introduced there is a rapid increase in the Angle of internal Friction i.e. $\Phi$.

\section{REFERENCES}

A. Carlson and T.-J. Liu, "Negative and iterated spacer lithography processes for low variability and ultra dense integration," in Proc. SPIE Optical Microlithography XXI, vol. 6924. 2008, pp. 69240B-1-69240B-9.

Athanasopoulos, G.A. (1996). Results of direct shear tests on geotextile reinforced cohesive soil, Geotextiles and Geomembranes, 14, pp. 619-644.

Danny jose Useche Infante, Gonzalo Martin Aiassa Martinez (2016), "Shear strength behaviour of different geosynthetic reinforced soil structure from direct shear test”, Switzerland.

Delmas, Ph., Gotteland, J.P., and Haidar, S. (1992). Two full size structures reinforced by geotextiles, in Grouting, Soil Improvement and Geosynthetics, ASCE, Geotechnical Special Publication No.30, ed. R.H. Borden,. R.D. Holtz and I. Juran, Vol.2. pp. 12011212.

G Madhavi Latha and Vidhya s Murthy (2007), "Effect of reinforcement form on the behaviour of geosynthetic reinforced sand", IISC, Bangalore.

Jewel, R.A., and Wroth, C.P. (1987). Direct shear tests on reinforced sand, Geotechnique, 37(1), pp.53-68.

Mofiz, S.A., Taha, M.R. and Sharker, D.C. "Mechanical stress-strain characteristics and model behaviour of geosynthetic reinforced soil composites", 17th ASCE Engineering Mechanics Conference, June 13-16, University of Delaware, Newark, DE, pp. 1-8 (2004).

Sanjay. K. Shukla, Nagaratnam Sivakugan, Braja. M. Das (2013), "Fundamental Concepts of Soil Reinforcement", Edith Cowan University, Joondalup.

Sayyed Mahdi Hejazi, Mohammad Sheikhzaadeh (2011), "A Simple Review of Soil Reinforcement by using Natural and Synthetic Fibres", Isfahan University of Technology, Isfahan

Temel Yetimoglu and Omer salbas (2002), "A study on shear strength of sands reinforced with randomly distributed discrete fibres", Turkey.

Y.T kim,H.J Kim,G.H.Lee (2008), "Mechanical behavior of lightweight soil reinforced with waste fishing net”, Pukyong and Kongju National Universities, Republic of Korea. 